\title{
Adsorption Dyes in Aqueous Solutions by Activated Carbon-Based White Wood
}

\author{
K. Elmerzouki ${ }^{1, *}$, I. Bimaghra ${ }^{1}$ and A. Khalidi ${ }^{2}$ \\ ${ }^{1}$ UH2C, Ecole Normale Supérieur, Laboratoire Ingénierie des Matériaux et Biosciences, Casablanca Morocco \\ ${ }^{2}$ UH2C, FST, Mohammedia, Morocco
}

\begin{abstract}
Among the dyes, the blue disperse and reactive orange have well recognized toxicities and dissemination facilities in the different compartments of the environment. Various regulations set maximum permissible levels of these dyes in both drinking water and industrial discharges. In order to comply with these various standards, many depollution techniques have been developed in recent years. Our choice is to carry out the adsorption of activated carbon based wood because this adsorption has main advantages of being more effective and easy to implement. Furthermore, the use of less expensive non-conventional adsorbents guarantees its economic feasibility. However, this elimination is affected by several parameters related to the carbon atom, to the solution and the active suspension. The adsorption results for Disperse Blue and orange reactive with activated charcoal showed adsorption capacity up to $4.8 \mathrm{mg} / \mathrm{g}$ and $12.4 \mathrm{mg} / \mathrm{g}$. The study showed that the adsorption of activated carbon prepared from wood is more effective for the removal of these two wastewater dyes.
\end{abstract}

Keywords: Activated carbon, dispersed Blue, Orange reagent, adsorption, waste water.

\section{INTRODUCTION}

In the textile industry various dyes are used. An important part is located downstream of the process circuits, in a discharge. These have varying degrees of harmfulness or high toxicity. This pollution is particularly dangerous because it is poorly understood. To fight against this dissolved pollution, research has been directed toward acceptable economic procédées by their low cost, using several techniques: adsorption on different materials [1-5], membrane filtration [5]. we study the use of charcoal made from wood mills in order to launder liquid discharges.

\section{RÉSULTATS ET DISCUSSIONS}

\subsection{Characterization of Two Dyes Studied}

A proper dye is a substance that has two specific independent properties to each other, the color and the ability to be fixed to a support such as a textile.

Table 1: Class of Dyes and Chemical Types (Zawlotzki, 2004)

\begin{tabular}{|c|c|c|c|}
\hline Class & substratum & Application Method & chemical type \\
\hline \hline Scattered & $\begin{array}{c}\text { Polyester, polyamide, } \\
\text { acetate, acrylic and plastic }\end{array}$ & $\begin{array}{c}\text { often fine aqueous dispersions applied by methods at } \\
\text { higher pressure and temperature or at a lower } \\
\text { temperature; the dye is fixed on the tissues thermally. }\end{array}$ & $\begin{array}{c}\text { Azo, Anthraquinones, styryl } \\
\text { group, nitro, benzo difuraones }\end{array}$ \\
\hline Reagent & Cotton, wool, silk and nylon & $\begin{array}{c}\text { Sitréactifs the dye reacts with the functional group on } \\
\text { the fiber to form a covalent bond under the influance } \\
\text { temperature and alkaline conditions. }\end{array}$ & $\begin{array}{c}\text { Azo, anthraquinones, } \\
\text { phthalocyanine, formazone and } \\
\text { oxacin }\end{array}$ \\
\hline
\end{tabular}

The removal of dye adsorption is considered one of the most adopted methods [3,4]. Industrially, the activated carbon is commonly used as adsorbent in the extraction of colored species in the liquid phase due to its excellent adsorption capacity, this capacity is related to its high surface area and porosity [1].

The valuation of useful substances (clay, sand, wood ...) is a major theme of research [2]. In this work,

*Correspondence Address to this author at the UH2C, Ecole Normale Supérieur, Laboratoire Ingénierie des Matériaux et Biosciences, Casablanca Morocco; Tel: 0662267222; E-mail: elmer_khad@yahoo.fr

\subsubsection{Classes of Dyes and Chemical Types Studied}

Synthetic dyes are of various nature and structure. The most frequently used chemical classes on an industrial scale are the azo compounds, anthraquinones, sulfur, indigo, triphénylmethyls, and phthalocyanines. However, it was stressed that the overwhelming majority of synthetic dyes currently used in industry are azo. The table below summarizes chemical structures and methods of application classes dyes studied in dye baths on substrates. 


\subsubsection{Determination Lengths Maximum Adsorption Wave}

To determine the maximum wavelength of absorption of both blue dye and reactive dispersion orange studied, we studied curves showing the optical densities OD at different wavelengths $\lambda$. The reference used is a solution of distilled water.

The curves shown schematically in Figures 1 and $\mathbf{2}$ are used to indicate that the values of the peak wavelength for the blue dispersion (BD) and the reactive orange $(\mathrm{OR})$ are $568 \mathrm{~nm}$ and $493 \mathrm{~nm}$ respectively.

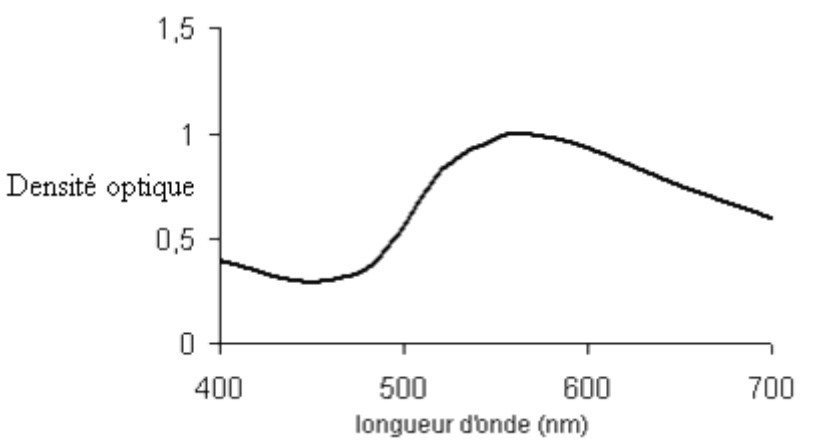

Figure 1: the peak wavelength of $\mathrm{BD}$.

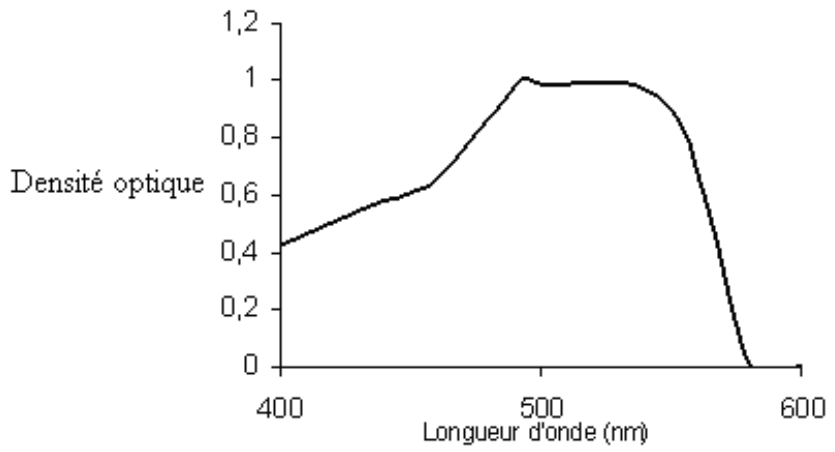

Figure 2: the peak wavelength of $O R$.

\subsubsection{Determination of Calibration Curves}

We plotted the calibration curves that give optical densities OD at different concentrations of both and dispersed orange reactive blue dye in water to lengths of respective maximum waves. Figures $\mathbf{3}$ and $\mathbf{4}$ show the calibration curves of the two dyes studied. The equations of these two curves are as follows:

${ }^{*}$ For blue disperses: OD $=0.012+3.877$ C 10-4;

${ }^{*}$ For the reactive orange: $\mathrm{OD}=0.015 \mathrm{C}$;

The treatment of activated carbon adsorption colored waters is influenced by the $\mathrm{pH}$ of the medium, the stirring time and the amount of activated carbon used.

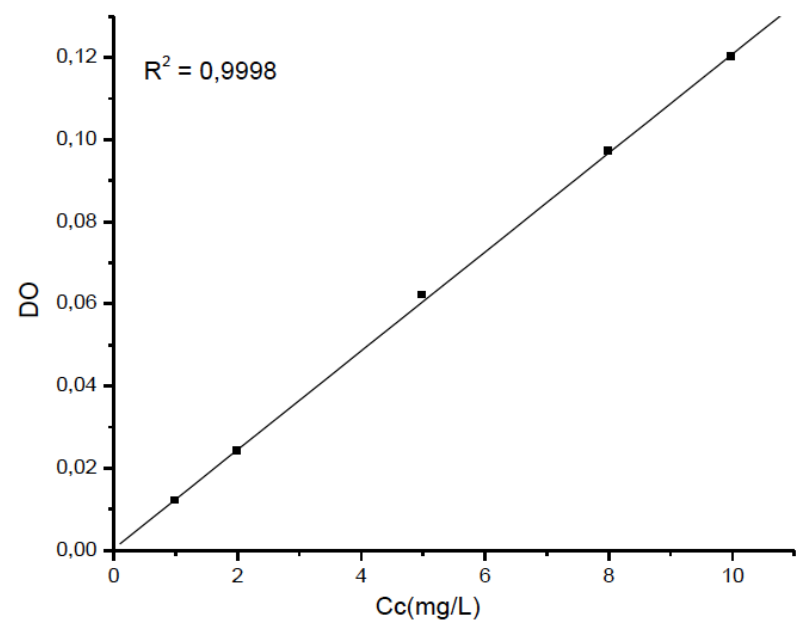

Figure 3: Calibration curve $O D=f(C) B D$.

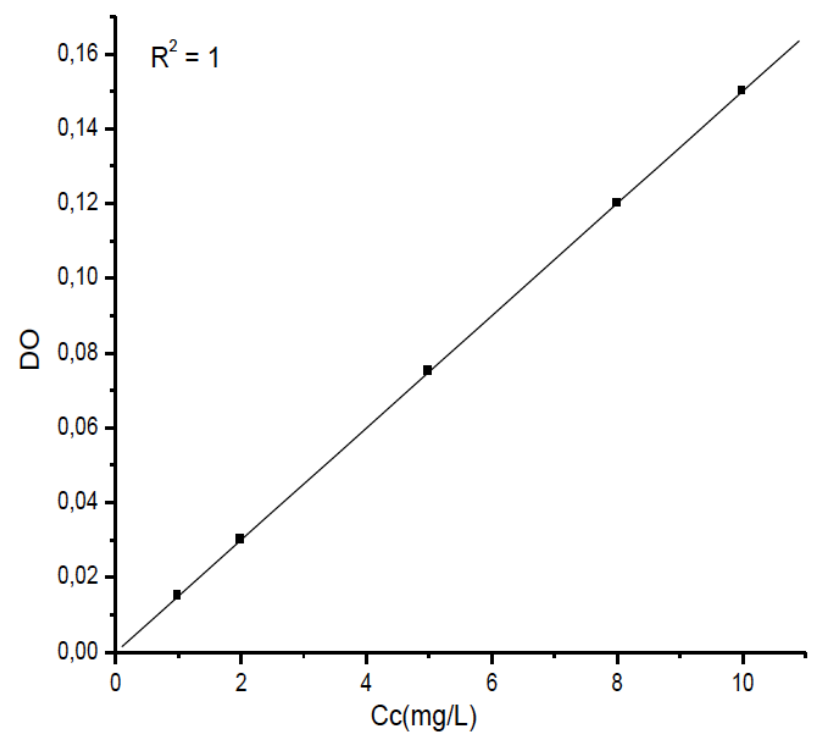

Figure 4: Calibration curve $O D=f(C) B D$.

\subsection{Effect of pH on the Adsorption of Dyes}

The adsorption of $\mathrm{BD}$ and $\mathrm{OR}$ by $\mathrm{CAB}$ was studied in a field caught between $\mathrm{pH} 0.6$ and 12 at room temperature, the initial concentration of the dye is 20 $\mathrm{mg} / \mathrm{L}$, the adsorbent mass is set to $02 \mathrm{~g}$ per $50 \mathrm{ml}$ of the dye solution and the stirring time is 60 minutes.

The two curves of Figure 5 reflect the variation in BD-adsorbing capacity and OR adsorbed by $\mathrm{CAB}$ depending on $\mathrm{pH}$. These results show that the acid $\mathrm{pH}$ favors adsorption, since its capacity is maximum, $4,28 \mathrm{mg} / \mathrm{g}$ for $\mathrm{BD}$ and $4,065 \mathrm{mg} / \mathrm{g} \mathrm{OR}, \mathrm{pH}=1.2$ for the two dyes. While at basic $\mathrm{pH}$ adsorption is unfavorable [8]. 


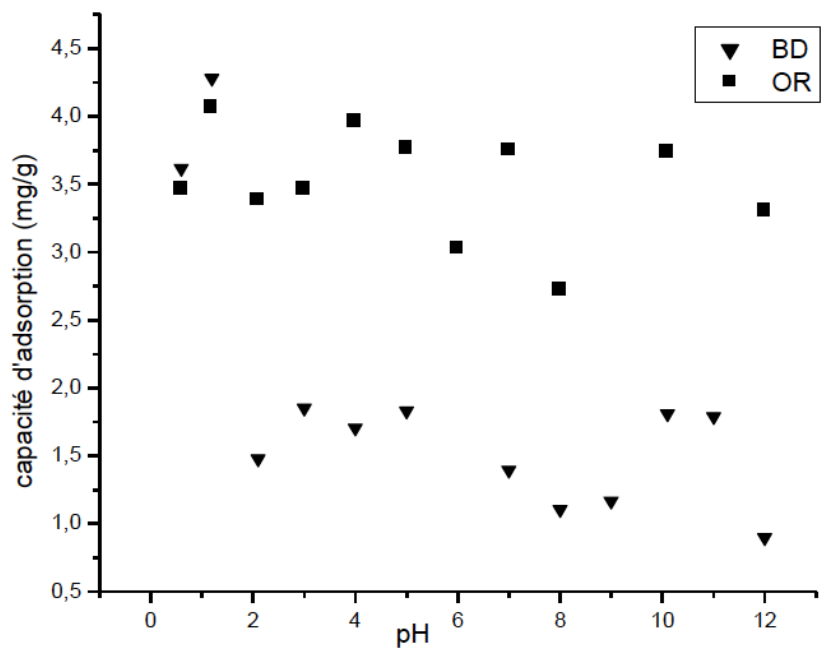

Figure 5: Effect of $\mathrm{pH}$ on the adsorption of $\mathrm{BD}$ and $\mathrm{OR}$ by $\mathrm{CAB} \mathrm{m}=0,2 \mathrm{~g} . \mathrm{CO}=20 \mathrm{mg} / \mathrm{L}, \mathrm{t}=1$ hour, $\mathrm{V}=\mathrm{v}=50 \mathrm{~mL}$ and $150 \mathrm{r} / \mathrm{min}$.

The $\mathrm{pH}$ of the solution influences the adsorbent surface, thus that the degree of ionization of pollutants. The hydronium ion $\mathrm{H}_{3} \mathrm{O}^{+}$and $\mathrm{OH}^{-}$hydroxide ions are strongly adsorbed and influences the adsorption of other ions. The change in $\mathrm{pH}$ has a great effect on the adsorption process, during the attachment of the functional group of the dye on the active sites of the adsorbent surface. This influences thereafter the reaction kinetics and adsorption equilibrium characteristics.

In the aqueous solution, the two studied dyes are dissolved and converted to the anionic ions. For the acid $\mathrm{pH}$, high rate of adsorption is due to strong electrostatic attractions between the positive charge of the adsorbent surface and the negative charge of the anionic dyes. To the basic $\mathrm{pH}$, there is competition between the $\mathrm{OH}^{-}$ions and the anions of $\mathrm{OR}$ and $\mathrm{BD}$ dyes for adsorption sites [8].

\subsection{Study the Adsorption Kinetics}

In Figure 6, we reported the adsorption curves obtained at room temperature for initial concentration solutions of $20 \mathrm{mg} / \mathrm{I}, \mathrm{Q}$ is the amount of the dye adsorbed in mg per gram of CAB.

The results showed that the BD dye is not completely removed during the time for the mass of 0.2 $\mathrm{g}$ of CAB used. The retention increases BD $4.018 \mathrm{mg} /$ $\mathrm{g}$ to stabilize at $4,40 \mathrm{mg} / \mathrm{g}$. Against by the OR dye is strongly adsorbed. At first, the retention increases OR of $3,94 \mathrm{mg} / \mathrm{g}$ and subsequently Revenue Is it a step to stabilize at $4,97 \mathrm{mg} / \mathrm{g}$.
The increase observed at baseline may be due to the fact that the adsorption is initially controlled by mass transfer, this transfer ensures diffusion of molecules of the dye to the grain surfaces of the cabinet through a liquid film surrounding the particles adsorbent. And stability of retention may be due to the saturation of the active sites $C A B$ [8].

The optimal time of adsorption of two dyes is about 120 minutes. It is found that the activated carbon has an affinity for both dyes and preferably in the order of $\mathrm{OR}$ and $\mathrm{BD}$.

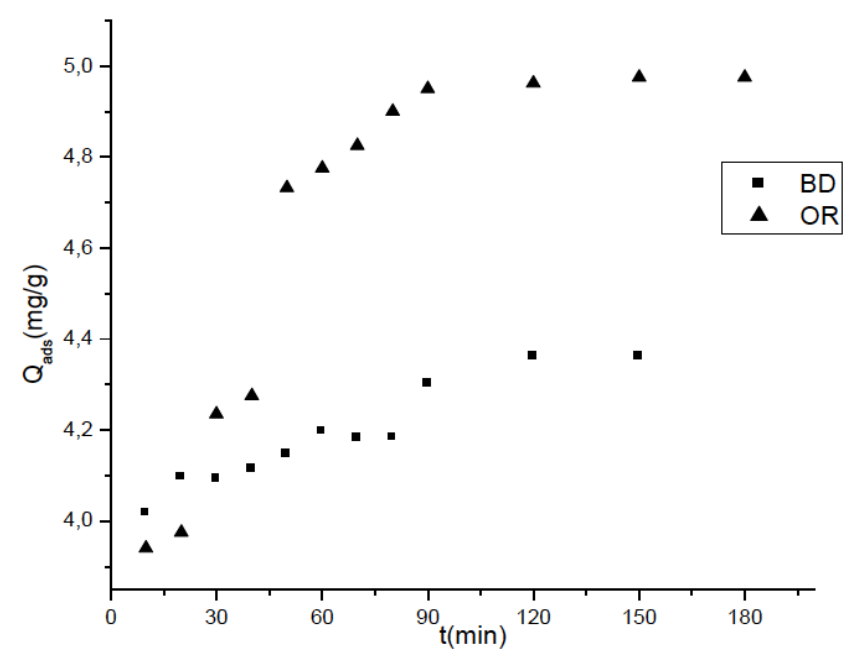

Figure 6: Variation of the adsorption capacity of the BD and OR function of time $\mathrm{pH}=1, \mathrm{~m}=0.2 \mathrm{~g}, \mathrm{CO}=20 \mathrm{mg} / \mathrm{L}, \mathrm{V}=$ $50 \mathrm{~mL}$ and $\mathrm{v}=700 \mathrm{rev} / \mathrm{min}$.

\subsection{Effect of Adsorbent Mass}

7 shows the variation of the concentration of the dye adsorbed by the cabinet according to the mass of the latter. From these results, we hold that the $O R$ is heavily eliminated by the CAB. The concentration of

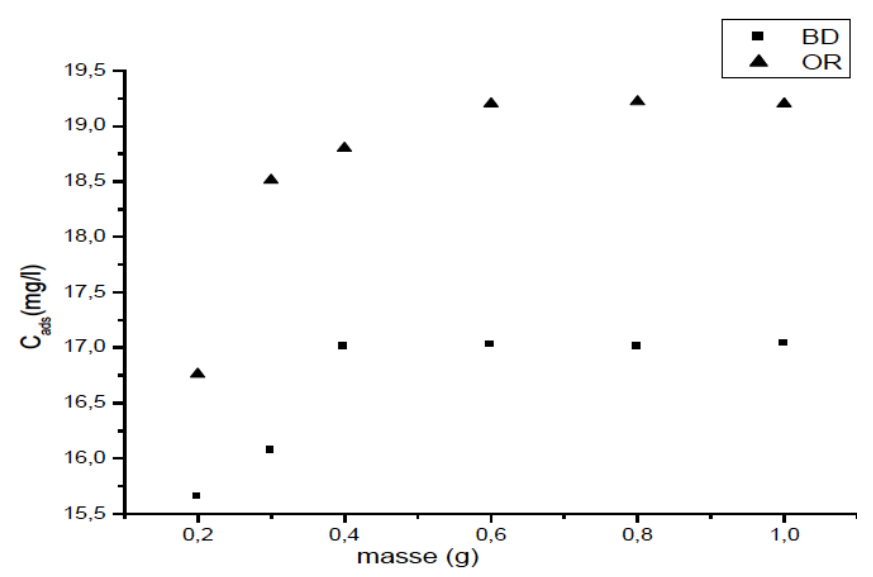

Figure 7: Effect of the mass of adsorbate on the adsorption of $\mathrm{BD}$ and $\mathrm{OR} \mathrm{pH}=1, \mathrm{t}=1$ hour, $\mathrm{CO}=20 \mathrm{mg} / \mathrm{L}, \mathrm{V}=\mathrm{v}=$ $50 \mathrm{~mL}$ and $200 \mathrm{rev} / \mathrm{min}$. 
adsorbed increases OR of $16.75 \mathrm{mg} / \mathrm{L}$ with the increase of the mass of the cabinet until the maximum value of $19.25 \mathrm{mg} / \mathrm{L}$. In result it remains constant with increasing the adsorbent mass.

Likewise for the blue dye dispersed $B D$ is less eliminated by the $C A B$. The concentration of adsorbed $\mathrm{BD}$ increases of $15.6 \mathrm{mg} / \mathrm{L}$ up to the maximum value of $17 \mathrm{mg} / \mathrm{L}$, and then remains constant.

Optimum amounts of $\mathrm{CAB}$ that we found are $0.6 \mathrm{~g}$ and $0.4 \mathrm{~g}$ of $\mathrm{CAB}$ for $50 \mathrm{ml}$ of the $\mathrm{OR}$ and $\mathrm{BD}$ solution respectively. The adsorption increases with the amount of adsorbent can be attributed to its increased surface area, and the availability of more the number of active sites with an increase in the weight of $C A B$ [9].

\section{CONCLUSION}

The study of adsorption of dyes has permit to show that the adsorption capacity is important for reactive orange dye and reached $4.97 \mathrm{mg} / \mathrm{g}$, i.e. $99 \%$ of reactive orange is adsorbed. She reached only 4,37 $\mathrm{mg} / \mathrm{g}$, meaning $87 \%$ of blue scatters is adsorbed. Kinetics is fast initially and subsequently slows to reach a level of equilibrium of adsorption. Time to saturation for two dyes is 120 minutes. The elimination of dyes by activated carbon shows that the adsorption process is important based on the mass of adsorbate. Optimized activated charcoal has an affinity for the two studied dyes and preferentially in order: orange, and blue reactive disperse.

\section{REFERENCES}

[1] Baran A, Bıçak E, Önal S, Baysal SH. Comparative studies on the adsorption of $\mathrm{Cr}(\mathrm{VI})$ ions on to various sorbents. Bioresource Technology 2006.

[2] Dumont R, et Gélus M. La valorisation chimique du bois, Ed. Masson, 1982; p. 167.

[3] Ju B, Xing G, Yang J, Zhang S. Study on adsorption behavior of crosslinked cationic starch maleate for chromium(VI). Carbohydrate Polymers, In Press, Corrected Proof 2006.

[4] Malkoc E, Nuhoglu Y, Abali Y. Cr(VI) adsorption by waste acorn of Quercus ithaburensis in fixed beds: Prediction of breakthrough curves. Chemical Engineering Journal, In Press, Corrected Proof 2006.

[5] Shawabkeh RA. Adsorption of chromium ions from aqueous solution by using activated carbo-aluminosilicate material from oil shale. Journal of Colloid and Interface Science, In Press, Corrected Proof 2006.

[6] Zawlotzki-Guivarch E. Traitement des pollutants organiques en milieu aqueux par procédé électrochimique d'oxydation avancée "Electro-Fenton ». Application à la minéralisation des colorants synthétiques. Marne-la-Vallée 2004.

[7] Alvarez F, Sondhi R, Lin YS. Crossflow filtration of chromium hydroxide suspension by ceramic membranes: Fouling and its minimization by backpulsing. Journal of Membrane Science 2000; 174: 111-122. http://dx.doi.org/10.1016/S0376-7388(00)00384-7

[8] Mall ID, Srivastava VC, Agarwal NK. Removal of Orange-G and Methyl Violet dyes by adsorption onto bagasse fly ashkinetic study and equilibrium isotherm analyses. Dyes and Pigments 2005; 69: 210-223. http://dx.doi.org/10.1016/j.dyepig.2005.03.013

[9] Mall ID, Srivastava VC, Agarwal NK, Mishra IM.. Removal of congo red from aqueous solution by bagasse fly ash and activated carbon: Kinetic study and equilibrium isotherm analyses. Chemospheres 2005; xxx: 1-10. 